\title{
EFEKTIVITAS METODE EDUKASI TRICKY CARD GAME DALAM MENINGKATKAN PENGETAHUAN LANSIA TERHADAP PENCEGAHAN HIPERTENSI DI SEKOLAH EYANG-EYANG KABUPATEN JEMBER
}

\section{THE EFFECTIVENESS OF TRICKY CARD GAMES EDUCATION METHODS TO IMPROVE ELDERLY'S KNOWLEDGE TOWARDS PREVENTION OF HYPERTENSION IN EYANG - EYANG SCHOOL JEMBER DISTRICT}

\author{
Karera Aryatika ${ }^{*}$, Ruli Bahyu Antika ${ }^{1}$, Dimas BC Cahyaningrat ${ }^{2}$ \\ ${ }^{1}$ Program Studi S1 Gizi, Fakultas Kesehatan Masyarakat, Universitas Jember \\ Jl. Kalimantan I/93, 68121, Jember, Jawa Timur, Indonesia \\ ${ }^{2}$ Progarm Studi S1 Ilmu Kesehatan Masyarakat, Fakultas Kesehatan Masyarakat, Universitas Jember \\ Jl. Kalimantan I/93, 68121, Jember, Jawa Timur, Indonesia \\ *email: kareraaryatika15@gmail.com
}

\begin{abstract}
East Java Province has a higher prevalence of hypertension (36.8\%) compared to the national prevalence (34.1\%) in 2018. The prevalence of hypertension in the elderly in the Ledokombo Jember sub-district was $41.88 \%$. The incidence of hypertension will continue to increase until the right solution is found to handle it. There will be a negative impact for people with hypertension, especially the elderly, its complications lead to death. The tricky card game educational method can be used as a solution in overcoming these problems. The design of this research is an intervention using a tricky card game method. This method includes four main activities such as interactive socialization, educational games, providing healthy life style guidance book also both consultation and measuring blood pressure. Respondents in this study were all members of the grandparent school in Ledokombo District, Jember Regency. The intervention was carried out for one month. The results of the intervention showed an increase in knowledge of the elderly to prevent hypertension ( $p$ value <0.05). There was an increase in the number of elderly who had a test score of $\geq 70$ before (33.33\%) and after (60\%) the intervention. There was a decrease in both systolic and diastolic blood pressure of the elderly before and after the intervention ( $p$ value <0.05). The number of elderly who experienced a decrease in systolic blood pressure was $66.67 \%$ and diastolic (33.3\%). Thus, the tricky card game educational method can be used as one of the alternative solution to prevent hypertension in the elderly.
\end{abstract}

Keywords: Tricky card game, Education Methods, Prevention of Hypertension, Elderly

\begin{abstract}
Abstrak
Provinsi Jawa Timur memiliki prevalensi hipertensi yang lebih tinggi (36.8\%) dibandingkan dengan prevalensi nasional (34.1\%) pada tahun 2018. Profil Kesehatan Kabupaten Jember (2016) menunjukkan bahwa jumlah penderita hipertensi primer pada usia lanjut yang ditangani puskesmas di Kabupaten Jember sebanyak 59.736 kasus sedangkan prevalensi hipertensi pada lanjut usia di kecamatan Ledokombo Kabupaten Jember sebesar 41,88\%. Kejadian hipertensi ini akan terus meningkat apabila tidak dicarikan solusi yang tepat dalam penanganannya. Padahal akan timbul beberapa dampak negatif bagi penderita hipertensi terutama lansia salah satunya timbulnya komplikasi yang berujung kepada kematian. Metode edukasi tricky card game dapat dijadikan sebagai solusi dalam mengatasi permasalahan tersebut. Desain penelitian ini adalah intervensi menggunakan metode
\end{abstract}


tricky card game. Metode edukasi tricky card game ini meliputi empat kegiatan inti antara lain penyuluhan yang interaktif, permainan yang edukatif, pemberian buku panduan hidup sehat bebas hipertensi dan konsultasi serta pengukuran tekanan darah. Responden dalam penelitian ini adalah seluruh anggota sekolah eyang - eyang di Kecamatan Ledokombo Kabupaten Jember. Intervensi dilakukan selama satu bulan. Hasil dari intervensi menunjukkan terdapat peningkatan pengetahuan lansia terhadap pencegahan hipertensi ( $p$ value $<0.05$ ). Terjadi peningkatan jumlah lansia yang memiliki nilai tes $\geq 70$ pada sebelum $(33.33 \%)$ dan sesudah $(60 \%)$ intervensi. Selain itu, terjadi penurunan tekanan darah baik sistolik maupun diastolik dari lansia sebelum dan sesudah intervensi ( $p$ value < 0.05). Jumlah lansia yang mengalami penurunan tekanan darah sistolik sebesar $66.67 \%$ dan distolik (33.3\%). Dengan demikian, metode edukasi tricky card game dapat dijadikan sebagai salah satu upaya untuk pencegahan hipertensi pada lansia.

Kata kunci: Tricky card game, Metode Edukasi, Pencegahan Hipertensi, Lansia

\section{PENDAHULUAN}

Hipertensi dikenal dengan sebutan "silent killer" yang jumlah penderitanya terus meningkat setiap tahunnya sehingga menjadi fenomena gunung es di Indonesia. Riskesdas (2018) menyebutkan terjadi peningkatan jumlah penderita hipertensi dari 25,8 persen (2013) menjadi 34.1 persen (2018) pada usia diatas 18 tahun. Prevalensi hipertensi di Indonesia pada kelompok umur tertentu seperti 55-64 tahun sebesar 45,9 persen, $57,6 \%$ umur 65-74 tahun dan $63,8 \%$ umur $>75$ tahun (Riskesdas RI, 2013). Provinsi Jawa Timur memiliki prevalensi hipertensi yang lebih tinggi (36.8\%) dibandingkan dengan prevalensi nasional (34.1\%) pada tahun 2018 (Riskesdas, 2013). Pengukuran tekanan darah pada usia diatas 18 tahun di Kabupaten Jember menunjukkan prevalensi sebesar 10.33\% (Dinkes Jatim, 2018). Profil Kesehatan Kabupaten Jember (2016) menunjukkan bahwa jumlah penderita hipertensi primer pada usia lanjut yang ditangani puskesmas di Kabupaten Jember sebanyak 59.736 kasus sedangkan prevalensi hipertensi pada lanjut usia di kecamatan Ledokombo Kabupaten Jember sebesar 41,88 \% (Dinkes Jember, 2013).

Lanjut usia (Lansia) merupakan kelompok masyarakat yang memiliki karakteristik yang berbeda dengan kelompok usia lain, hal ini disebabkan lansia umumnya mengalami penurunan fungsi fisik, sosial, dan psikologis. Meningkatnya kejadian hipertensi yang sering dialami lanjut usia disebabkan oleh perubahan fisiologis yang mulai menurun seiring dengan bertambahnya usia, fungsi organ tubuh akan mulai menurun baik karena alamiah atau karena penyakit. Sistem kardiovaskular mengalami penurunan elastisitas pada dinding aorta, katup jantung menebal dan menjadi kaku, serta berkurangnya kemampuan jantung untuk memompa darah. Akibat dari semua penurunan fungsi system kardiovaskular tersebut, terjadi penurunan kontraksi dan volume darah, hilangnya elastisitas pembuluh darah, kurangnya efektivitas pembuluh darah perifer untuk oksigenisasi, serta terjadinya hipertensi akibat meningkatnya resistensi pembuluh darah perifer (Kemenkes RI, 2017). Oleh sebab itu, semakin bertambahnya usia erat kaitannya dengan peningkatan tekanan darah baik sistolik maupun diastolik.

Hipertensi yang dialami oleh lanjut usia ini memiliki beberapa dampak negatif diantaranya apabila tidak mendapatan penanganan yang benar dapat menimbulkan komplikasi penyakit seperti stroke, gagal jantung, infark myocard hingga koma. Sedangkan perawatan komplikasi dari hipertensi membutuhkan biaya yang tidak sedikit dan hal tersebut menjadi tanggungan dan beban keuangan keluarga. Selain itu, hipertensi dapat menurunkan keaktifan dan produktivitas dari lanjut usia itu sendiri (Pical, 2011)

Definisi lanjut usia (lansia) berdasarkan Peraturan Pemerintah Republik Indonesia Nomor 43 tahun 2004 adalah penduduk dengan umur 60 tahun keatas. Terdapat 19 provinsi di Indonesia yang memiliki struktur penduduk tua pada tahun 2017. Adapun provinsi Jawa Timur termasuk ke dalam 3 besar provinsi dengan penduduk usia lanjut terbanyak (12,25\%) (Suhartini, 2017). Kabupaten Jember sendiri memiliki jumlah penduduk usia lanjut sebesar 656.952 jiwa (Kemenkes RI, 2017). Salah satu populasi masyarakat lansia yang berada di Kabupaten Jember adalah kelompok lansia di Kecamatan Ledokombo.

Kecamatan Ledokombo merupakan salah satu kecamatan di kabupaten Jember dengan kondisi masyarakat yang beragam. 
Kecamatan Ledokomo terdiri dari 10 desa meliputi Karangpaiton, Lembengan, Ledokombo, Suren, Slateng, Sumbersalak, Sumberlesung, Sumberanget, Sumberbulus dan Sukogidri. Kondisi geografis sebagian besar adalah persawahan dan tegalan. Beberapa wilayah terdiri dari dataran tinggi dan perbukitan (BPS, 2016).

Kecamatan Ledokombo memiliki perkumpulan lanjut usia yang tergabung dalam suatu wadah yang dinamakan "Sekolah Yang Eyang”. Sekolah Yang - Eyang ini digagas oleh Karang Werda Bungur Desa Sumberlesung dan komunitas Tanoker serta beranggotakan sekitar 40 peserta lanjut usia. Sekolah Yang - Eyang ini hadir atas semangat bersama untuk menjadi lansia berkualitas dan membentuk generasi emas.

Kegiatan yang dilakukan oleh peserta sekolah Yang Eyang antara lain olahraga bersama, mengaji bersama dan juga belajar bersama. Mereka belajar cara mengasuh, mendidik dan pemenuhan hak anak (cucu) yang baik (karena mayoritas orangtua bekerja sebagai buruh migran dan menitipkan anaknya kepada nenek atau kakek mereka), membuat kreatifitas menu makanan baru, serta mengikuti berbagai pelatihan seperti kewirausahaan dan penggunaan internet.

Namun sekolah Yang Eyang ini masih bergerak di bidang pemberdayaan lanjut usia secara umum dan belum berfokus terhadap pelatihan kesehatan untuk lansia seperti pencegahan timbulnya penyakit tidak menular yang biasa dialami lansia, edukasi berbagai macam penyakit tidak menular yang biasa dialami oleh lansia salah satunya hipertensi, perawatan dan penanganan terhadap penderita serta gizi seimbang pada lanjut usia.

\section{METODE PENELITIAN}

Jenis penelitian yang digunakan dalam penelitian ini adalah penelitian intervensi dengan menggunakan metode edukasi tricky card game. Analisis data menggunakan SPSS Version 20.0. Pengujian perbedaan tingkat pengetahuan sebelum dan sesudah intervensi menggunakan paired sample t-test. Untuk pengukuran tingkat pengetahuan dari lansia digunakan kuesioner terstruktur yang sudah divalidasi. Lansia diminta untuk mengisi kuesioner tersebut sebelum dan sesudah intervensi dilakukan. Metode edukasi tricky card game ini meliputi pemberian sosialiasasi tentang pencegahan hipertensi, permainan edukatif dan atraktif, pemberian buku yang berisi panduan hidup sehat bebas hipertensi. Selain itu dalam metode ini diadakan senam lansia sehat setiap seminggu $2 x$ pada hari rabu dan jumat. Pengukuran perubahan tekanan darah pada lansia dilakukan sebelum dan setelah dilakukan intervensi ini.

Kegiatan diawali dengan pengukuran tekanan darah pda lansia. Dilanjutkan dengan senam lansia, setelah itu penyuluhan. Sebelum penyuluhan dilakukan, diberikan pre test untuk mengetahui sejauh mana pengetahuan yang eyang terhadap hipertensi.

Penyuluhan dilakukan dengan metode ceramah, tanya jawab dan diskusi antara peneliti dan para lansia. Materi disampaikan dengan menggunakan power point dan setiap lansia mendapatkan hard copy. Materi yang disampaikan antara lain pengertian hipertensi dan gejalanya, dampak hipertensi, pencegahan hipertensi dan penanganan serta perawatan penderita hipertensi. Sesi ini berlangsung selama 45 menit. Penyuluan selesai dilakukan, kemudian dilanjutkan dengan post test. Post test memuat pertanyaan yang sama dengan pre test, tujuannya untuk melihat apakah yang eyang telah mengerti dengan materi yang disampaikan. Materi adalah pedoman umum gizi seimbang (PUGS) tahun 2014 dan masalah gizi pada lansia.

Kegiatan dilanjutkan dengan permainan yang kita sebut "TRICKYCARD GAME". Permainan dibagi menjadi 4 kelompok. Setiap anggota kelompok diajak untuk memilih gambar makanan atau minuman yang dilarang, diperbolehkan, dan dibatasi konsumsinya. Setelah permainan dibagikan doorprize untuk peserta berupa bahan sembako.

Kemudian diberikan buku panduan hidup sehat bebas hipertensi kepada lansia agar dilakukan penerapannya setiap hari. Buku didalamnya termasuk terdapat menu - menu masakan yang bisa dipraktekan untuk mencegah kejadian hipertensi.

Setelah mencapai minggu ke empat dilakukan follow up kepada lansia di sekolah eyang-eyang. Dalam follow up ini dilakukan wawancara terstruktur, konsultasi gizi, pengukuran tekanan darah serta sosialisasi kembali. Lansia diminta untuk mengisi kuesioner pre dan post test sebelum dan sesudah sosialisasi.

Penelitian ini dilakukan selama 4 minggu pada bulan September 2019. Total populasi lansia yang bergabung dalam sekolah 
eyang - eyang berjumlah 30 orang. Seluruh anggota dari sekolah eyang - eyang ini adalah perempuan.

\section{HASIL DAN PEMBAHASAN}

\section{Karakteristik Lansia di sekolah Eyang -} Eyang.

Lansia yang bergabung di Sekolah Eyang-eyang memiliki karakteristik sosio ekonomi yang beragam. Berikut kami sajikan table karakteristik sosio ekonomi dari lansia di sekolah Eyang-eyang.

Tabel 1. Karakteristik Responden

\begin{tabular}{|c|c|c|}
\hline $\begin{array}{c}\text { Karakteristik } \\
\text { Responden }\end{array}$ & $\begin{array}{c}\text { Jumlah } \\
(\mathrm{n}=30)\end{array}$ & $\begin{array}{c}\text { Persentase } \\
(\%)\end{array}$ \\
\hline \multicolumn{3}{|l|}{ Pekerjaan } \\
\hline Ibu Rumah Tangga & 24 & 80 \\
\hline \multicolumn{3}{|l|}{ Usia } \\
\hline $50-60$ tahun & 12 & 40 \\
\hline $60-70$ tahun & 15 & 50 \\
\hline $70-80$ tahun & 3 & 10 \\
\hline \multicolumn{3}{|l|}{ Pendidikan } \\
\hline $\mathrm{SD}$ & 5 & 16.67 \\
\hline SMP & 15 & 50 \\
\hline SMA & 8 & 26.67 \\
\hline PT & 2 & 6.66 \\
\hline \multicolumn{3}{|l|}{ Kebiasaan Merokok } \\
\hline Merokok & 0 & 0 \\
\hline Tidak Merokok & 30 & 100 \\
\hline \multicolumn{3}{|l|}{ Kebiasaan Minum } \\
\hline Alkohol & & \\
\hline Minum Alkohol & 0 & 0 \\
\hline Tidak Minum Alkohol & 30 & 100 \\
\hline \multicolumn{3}{|l|}{ Kebiasaan } \\
\hline \multicolumn{3}{|l|}{ Mengkonsumsi } \\
\hline \multicolumn{3}{|l|}{ Gorengan } \\
\hline $\begin{array}{l}\text { Mengkonsumsi } \\
\text { gorengan 1x sehari }\end{array}$ & 10 & 33.33 \\
\hline $\begin{array}{l}\text { Mengkonsumsi } \\
\text { gorengan }>1 \mathrm{x} \text { sehari }\end{array}$ & 20 & 66.67 \\
\hline \multicolumn{3}{|l|}{$\begin{array}{l}\text { Kebiaaan konsumsi } \\
\text { buah dan sayur }\end{array}$} \\
\hline $\begin{array}{l}\text { Mengkonsumsi buah } \\
\text { dan sayur sehari } 3 \mathrm{x}\end{array}$ & 14 & 46.67 \\
\hline $\begin{array}{l}\text { Mengkonsumsi buah } \\
\text { savur sehari < } 3 \mathrm{x}\end{array}$ & 16 & 53.33 \\
\hline
\end{tabular}

Berdasarkan tabel diatas dapat diketahui bahwa lebih dari $50 \%$ anggota dari sekolah Eyang-eyang memiliki usia 60-70 tahun. Mayoritas mereka merupakan ibu rumah tangga dan berpendidikan paling banyak berasal dari SMP.

Tidak ada anggota sekolah eyangeyang yang memiliki kebiasaan merokok dan mengkonsumsi minuman beralkohol. Untuk riwayat kebiasaan makan lebih dari $50 \%$ anggota memiliki kegemaran mengkonsumsi gorengan lebih dar $1 \mathrm{x}$ sehari dan rendahnya konsumsi buah dan sayur.

\section{Tekanan Darah Lansia Sebelum dan} Sesudah Intervensi.

Hasil dari pengukuran tekanan darah sebelum dan sesudah intervensi ditampilkan dalam tabel berikut.

Tabel 2. Tekanan Darah Lansia Sebelum dan Sesudah Intervensi

\begin{tabular}{|c|c|c|c|c|c|}
\hline \multirow[t]{2}{*}{$\begin{array}{l}\mathrm{N} \\
\mathrm{O}\end{array}$} & \multirow[t]{2}{*}{$\begin{array}{c}\text { Nam } \\
\mathrm{a}\end{array}$} & \multicolumn{2}{|c|}{$\begin{array}{c}\text { Tekanan Darah } \\
\text { Sebelum } \\
\text { Intervensi }\end{array}$} & \multicolumn{2}{|c|}{$\begin{array}{c}\text { Tekanan Darah } \\
\text { Sesudah } \\
\text { Intervensi }\end{array}$} \\
\hline & & $\begin{array}{c}\text { Sistoli } \\
\mathrm{k}\end{array}$ & $\begin{array}{c}\text { Diastoli } \\
\mathrm{k}\end{array}$ & $\begin{array}{c}\text { Sistoli } \\
\mathrm{k}\end{array}$ & $\begin{array}{c}\text { Diastoli } \\
\text { k }\end{array}$ \\
\hline 1 & $\mathrm{Jm}$ & 119 & 74 & 122 & 68 \\
\hline 2 & $\mathrm{Mh}$ & 172 & 93 & 163 & 97 \\
\hline 3 & $\mathrm{Sh}$ & 180 & 97 & 170 & 97 \\
\hline 4 & SS & 120 & 70 & 126 & 70 \\
\hline 5 & $\operatorname{Tn}$ & 146 & 96 & 188 & 95 \\
\hline 6 & In & 180 & 90 & 183 & 103 \\
\hline 7 & Wk & 120 & 69 & 127 & 65 \\
\hline 8 & $\mathrm{Nn}$ & 173 & 93 & 171 & 89 \\
\hline 9 & Es & 145 & 91 & 142 & 87 \\
\hline 10 & $\mathrm{Sa}$ & 155 & 99 & 150 & 97 \\
\hline 11 & Wi & 146 & 85 & 147 & 90 \\
\hline 12 & $\mathrm{Rm}$ & 175 & 100 & 180 & 106 \\
\hline 13 & $\mathrm{Sp}$ & 156 & 84 & 130 & 75 \\
\hline 14 & Ss & 155 & 77 & 135 & 75 \\
\hline 15 & $\mathrm{Jm}$ & 114 & 69 & 118 & 70 \\
\hline 16 & My & 150 & 80 & 141 & 80 \\
\hline 17 & $\mathrm{Sn}$ & 130 & 80 & 127 & 69 \\
\hline 18 & St & 182 & 92 & 127 & 69 \\
\hline 19 & Mt & 140 & 80 & 137 & 79 \\
\hline 20 & Sk & 121 & 87 & 117 & 68 \\
\hline 21 & Ts & 141 & 94 & 136 & 84 \\
\hline 22 & Es & 140 & 80 & 136 & 72 \\
\hline 23 & $\mathrm{Jh}$ & 127 & 77 & 120 & 70 \\
\hline 24 & $\mathrm{Tt}$ & 176 & 112 & 174 & 99 \\
\hline 25 & $\mathrm{Ft}$ & 150 & 90 & 140 & 85 \\
\hline 26 & $\mathrm{Kl}$ & 140 & 80 & 125 & 70 \\
\hline 27 & $\mathrm{Pt}$ & 120 & 80 & 110 & 75 \\
\hline 28 & $\mathrm{Jk}$ & 110 & 80 & 100 & 75 \\
\hline 29 & Rs & 125 & 90 & 120 & 80 \\
\hline 30 & $\mathrm{Kn}$ & 150 & 100 & 140 & 95 \\
\hline
\end{tabular}

Dari tabel tersebut dapat diketahui bahwa ada perubahan sebelum kegiatan metode edukasi tricky card game dengan setelah kegiatan dilakukan pada tekanan darah Lansia di sekolah Eyang-Eyang. Tekanan darah sistolik yang turun sebanyak 20 orang (66.67\%) dan distolik sebanyak 10 orang (33.3\%). Ini membuktikan bahwa ada pengaruh setelah 
dilakukannya penyuluhan dan permainan tricky card game.

\section{Tingkat Pengetahuan Lansia Mengenai Pencegahan Hipertensi Sebelum dan Setelah Intervensi}

Dalam pengukuran tingkat pengetahuan lansia sebelum dan setelah intervensi dilakukan pre dan post tes. Lansia diminta untuk mengisi kuesioner terstruktur terdiri dari 25 pertanyaan yang sudah divalidasi sebelumnya. Hasil perhitungan nilai dapat digunakan sebagai patokan adanya peningkatan pengetahuan mengenai pencegahan hipertensi pada lansia.

Tabel 3. Hasil Pre dan Post Tes Lansia Mengenai Pencegahan Hipertensi

\begin{tabular}{lcc}
\hline \multicolumn{1}{c}{ Hasil } & $\begin{array}{c}\text { Jumlah } \\
(\mathbf{N}=\mathbf{3 0})\end{array}$ & $\begin{array}{c}\text { Persentase } \\
(\boldsymbol{\%})\end{array}$ \\
\hline Pre Test & & \\
Nilai $\geq 70$ & 10 & 33.33 \\
Nilai $<70$ & 20 & 66.67 \\
Post Test & & \\
Nilai $\geq 70$ & 18 & 60 \\
Nilai $<70$ & 12 & 40 \\
\hline
\end{tabular}

Berdasarkan tabel diatas terlihat terdapat peningkatan jumlah lansia yang memiliki nilai tes $\geq 70$ pada pre $(33.33 \%)$ dan post test $(60 \%)$.

\section{Efektivitas Metode Edukasi Tricky card game Terhadap Pencegahan Hipertensi Pada Lansia}

Lansia mengalami peningkatan pengetahuan terhadap pencegahan hipertensi berdasarkan hasil pre dan post test sebelum dan setelah intervensi. Hal tersebut dapat dilihat melalui jumlah lansia yang mampu menjawab benar dari setiap pertanyaan yang diberikan melalui kuesioner terstruktur yang sudah divalidasi (memiliki nilai $\geq 70$ ). Hasil uji paired sample t-test menunjukkan terdapat hubungan yang signifikan antara hasil pre dan post test ( $p$ $<0.05)$.

Lansia sangat antusias dalam mengikuti setiap kegiatan yang dilakukan oleh tim penelitian. Termasuk melakukan secara rutin kegiatan senam sehat lansia yang akan diadakan secara berkala setiap 2x seminggu. Selain itu, lansia juga mempraktekkan resep-resep masakan yang tercantum dalam buku panduan hidup sehat yang tim susun.

Tingkat partisipasi dan keaktifan cukup tinggi dengan banyaknya pertanyaan yang diajukan oleh lansia kepada tim didorong rasa keingin tahuan dan keinginan belajar yang lebih dari para lansia. Antusiasme lain terlihat dari menurunnya keluhan yang dialami oleh lansia pada saat konsultasi gizi pada minggu pertama dan pada minggu keempat.

Selanjutnya untuk membuat program ini tetap berkelanjutan tim memilih seorang duta hipertensi kepada salah satu eyang-eyang yang paling aktif dan memiliki nilai terbaik dari hasil pre dan post test. Tugas dari duta hipertensi ini adalah mengingatkan para lansia yang lain baik yang tergabung dalam sekolah eyang-eyang maupun tidak agar selalu menjaga pola hidup sehat dan bebas hipertensi.

Dari hasil pengukuran tekanan darah juga menunjukkan adanya perubahan yang signifikan antara tekanan darah baik sistolik maupun diastolik sebelum dan setelah intervensi dengan uji paired sample t-test ( $p$ value < 0.05 ).

Hipertensi adalah kondisi di mana tekanan darah lebih tinggi dari 140/90 milimeter merkuri (mmHG). Angka 140 mmHG merujuk pada bacaan sistolik, ketika jantung memompa darah ke seluruh tubuh. Sementara itu, angka $90 \mathrm{mmHG}$ mengacu pada bacaan diastolik, ketika jantung dalam keadaan rileks sembari mengisi ulang bilik-biliknya dengan darah. Perlu diketahui bahwa tekanan sistolik adalah tekanan maksimal karena jantung berkontraksi, sementara tekanan diastolik adalah tekanan terendah di antara kontraksi (jantung beristirahat).

Hipertensi dapat mengakibatkan komplikasi serius penyakit jantung koroner, gagal jantung, stroke, gagal ginjal, kebutaan, diabetes, dan banyak penyakit berbahaya lainnya. Stroke $(51 \%)$ dan penyakit jantung koroner $(45 \%)$ merupakan penyebab kematian akibat hipertensi tertinggi di Indonesia.

Hipertensi yang penyebabnya tidak jelas disebut hipertensi primer. Tapi tekanan darah tinggi juga bisa disebabkan oleh gaya hidup dan pola makan yang buruk. Kebanyakan makan makanan asin, yang mengandung natrium (makanan olahan, makanan kalengan, fast food), dan makanan atau minuman yang mengandung pemanis buatan juga dapat meningkatkan kolesterol dan/atau tekanan darah tinggi.

\section{KESIMPULAN DAN SARAN}

\section{Kesimpulan}

Metode Edukasi Tricky card game mampu meningkatkan pengetahuan lansia 
terhadap pencegahan hipertensi. Oleh karena itu, metode ini dapat dijadikan sebagai salah satu alternatif dalam upaya pemerintah menurunkan kejadian penyakit degeneratif di Indonesia.

\section{Saran}

Untuk saran kedepan dalam penggunaan metode ini sebaiknya dilakukan kontrol tekanan darah pada lansia setiap seminggu sekali dan konsultasi gizi satu bulan $2 x$. Serta selalu melakukan penyegaran informasi dan update ilmu baru terhadap lansia minimal 1 bulan $1 \mathrm{x}$.

\section{DAFTAR PUSTAKA}

1] Badan Pusat Statistik. 2016. Kecamatan Ledokombo Dalam Angka. https://jemberkab.bps.go.id/publication/20 16/07/29/714578e43f83ecca869a006e/keca matan-ledokombo-dalam-angka2016.html.

2] Dinas Kesehatan Kabupaten Jember. 2017. Profil Kesehatan Kabupaten Jember tahun 2016.http://www.depkes.go.id/resources/d ownload/profil/PROFIL_KAB_KOTA_20 16/3509_Jatim_Kab_Jember_2016.pdf BPS. 2017. Kota Surabaya dalam Angka 2018.

3] Dinas Kesehatan Provinsi Jawa Timur. 2018. Profil Kesehatan Provinsi Jawa Timur tahun 2017. http://www.depkes.go.id/resources/downlo
ad/profil/PROFIL_KES_PROVINSI_2017 /15_Jatim_2017.pdf.

4] Kementrian Kesehatan Republik Indonesia. 2013. Riskesdas 2013.http://www.depkes.go.id/resources/d ownload/general/Hasil\%20Riskesdas\%202 013.pdf.

5] Kementrian Kesehatan Republik Indonesia. 2017. Analisis Lansia di Indonesia.http://www.depkes.go.id/downlo ad.php?file=download/pusdatin/lainlain/Analisis Lansia Indonesia.

6] Kementrian Kesehatan Republik Indonesia. 2018. Hasil Utama Riskesdas 2018.http://www.depkes.go.id/resources/d ownload/infoterkini/materi_rakorpop_2018 /Hasil\%20Riskesdas\%202018.pdf.

7] Nugroho, Wahjudi. 2000. Keperawatan Gerontik. 32. EGC: Jakarta.

8] Pical, Femy Emilia. 2011. Prevalensi dan Determinan Hipertensi di Posyandu Lansia Wilayah Keamatan Pasar Rebo Jakarta Timur tahun 2010. Skripsi. Universitas Indonesia.Depok

9] Suhartini et.al. 2017.Profil Tekanan Darah Pada Lansia di Kecamatan Arjasa Kabupaten Jember. Warta Pengabdian.2(4): 170-176 